\title{
EVALUATION OF STRESS AND ITS INFLUENCE ON QUALITY OF LIFE IN POSTMENOPAUSAL WOMEN
}

\author{
JAYABHARATHI B* \\ Department of Obstetrics and Gynecology Nursing, SRM College of Nursing, SRM University, Chennai, Tamil Nadu, India. \\ Email: jayabharathimariyappan23@gmail.com
}

Received: 17 June 2016, Revised and Accepted: 29 June 2016

\section{ABSTRACT}

Background: Menopause is a stage in life when a woman stops having her monthly period. It is a normal part of aging and marks the end of a woman's reproductive years. The age of menopause varies from 45 to 50 years. In some woman, the age of menopause may be 51 or 52 years.

Aim: This study aims to evaluate the stress and its influence on quality of life (QOL) in postmenopausal women in selected areas, Kattankulathur Block, Chennai, Tamil Nadu, India.

Methods: A cross-sectional study was conducted in selected areas in Kattankulathur Block, Chennai, Tamil Nadu. After initial screening, simple random sampling technique was adopted to select the study participants. The total sample size comprised 130 postmenopausal women. Assessments were made by Sheldon Cohen's, the Perceived Stress Scale for assessing the stress level of postmenopausal women and the World Health Organization QOL-BREF Scale for assessing their QOL.

Results: This study showed that the majority of postmenopausal women $90(70.4 \%)$ had very high level of stress. Maximum of postmenopausal women 56 (44\%) had very poor QOL, and 59 (46\%) were very dissatisfied about their health status. The lower mean scores were found in physical, psychological, social, and environment domain among postmenopausal women. There was moderate negative correlation found between stress and QOL among postmenopausal women. It shows that, when the stress was increased, poor QOL was experienced by postmenopausal women.

Conclusion: This study results showed that the majority of postmenopausal women 90 (70.4\%) had very high level of stress which negatively affected the QOL of postmenopausal women.

Keywords: Stress, Quality of life, Postmenopausal women.

(C) 2016 The Authors. Published by Innovare Academic Sciences Pvt Ltd. This is an open access article under the CC BY license (http://creativecommons. org/licenses/by/4. 0/) DOI: http://dx.doi.org/10.22159/ajpcr.2016.v9s2.13539

\section{INTRODUCTION}

Menopause is a stage in life when a woman stops having her monthly period. It is a normal part of aging and marks the end of a woman's reproductive years. Menopause typically occurs in a woman's late 40 s to early 50s. However, women who have their ovaries surgically removed undergo "sudden" menopause [1]. Medical professionals often define menopause as having occurred when a woman has not had any vaginal bleeding for a year. It may also be defined by a decrease in hormone production by the ovaries. In those who have had surgery to remove their uterus but they still have ovaries, menopause may be viewed to have occurred at the time of the surgery or when their hormone levels fell. Following the removal of the uterus, symptoms typically occur earlier, at an average of 45 years of age [2].

Before menopause, a woman's periods typically become irregular, which means that periods may be longer or shorter in duration, or be lighter or heavier in terms of the amount of flow. During this time, women often experience hot flashes; these typically last from 30 seconds to 10 minutes, and may be associated with shivering, sweating, and reddening of the skin. Hot flashes often stop occurring after a year or two. Other symptoms may include vaginal dryness, trouble sleeping, and mood changes. The severity of symptoms varies between women. While menopause is often thought to be linked to an increase in heart disease, this primarily occurs due to increasing age and does not have a direct relationship with menopause. In some women, problems that were previously present like endometriosis or painful periods will improve after menopause [2].

Many women find the time around menopause stressful. This may be partially due to hormonal changes and resulting bothersome symptoms such as hot flashes and disrupted sleep. In addition, family and personal issues such as the demands of teenage children, children leaving home, aging parents, midlife spouses, and career changes often converge on women during these years. Chronic stress is not good for anyone's health. It may cause increased blood pressure and heart rate, headaches, gastric reflux, depression/anxiety, and over the long-term, an increased risk for heart disease. Some believe that chronic stress may affect the immune system, making the people more susceptible to illness, infections, and even cancer. Stress affects not only the health but also the relationships, work performance, general sense of well-being, and quality of life (QOL) [3]. Stress is now considered a significant contributor to poor health and important factor in the development of heart diseases, cancer, and many chronic and acute diseases. Most modern day, stress reduction techniques have their roots in yoga and its emphasis on the health and deep relaxation $[4,5]$.

QOL has been defined by the World Health Organization (WHO) as the "individual's perceptions of their position in life in the context of the cultural and value systems in which they live and in relation to their goals, expectations, standards, and concerns." It is a broad ranging concept incorporating in a complex way the persons' physical health, psychological state, level of independence, social relationships, personal beliefs, and their relationships to salient features of the environment. This definition reflects the view that QOL refers to a subjective evaluation, which is embedded in a cultural, social, and environmental context. QOL is the main goal of health care and a significant factor for individual health and it is used to plan and evaluate health-care programs [6,7].

Conde et al. done a study to evaluate QOL and identify its associated factors in postmenopausal women. A cross-sectional study was 
conducted among 81 postmenopausal women. QOL was assessed by the medical outcomes study 36-item Short Form Health Survey (SF-36) questionnaire. The most prevalent symptoms were nervousness (67\%) and hot flushes and sweating (51\%). Factors associated with poorer QOL were sweating, palpitations, nervousness (physical component), and dizziness, nervousness, depression, insomnia, and dyspareunia (mental component). They observed that menopausal symptoms negatively affected the physical and mental components of QOL in postmenopausal women [8].

Menopause does not really require medical treatment since it is a natural biological process. The menopause treatments actually focus on relieving the symptoms of menopause and in preventing any chronic condition that may occur during the postmenopausal years such as heart disease and osteoporosis. Exercising, proper diet, not smoking, and reduction of stress are also effective ways to make menopause more bearable and also facilitate in preventing any chronic ailments that can occur in the postmenopausal years [9].

The menopause is a stressful stage for some women. Strategies for managing stress can help women cope not only with menopause, but with life and also aging in general. Practices including relaxation exercises, biofeedback, aerobic exercise, yoga, meditation, and breathing techniques give women tools for dealing with their stressful lives [10].

This study aims to evaluate the stress and its influence on QOL in postmenopausal women in selected areas, Kattankulathur Block, Chennai, Tamil Nadu, India.

\section{METHODS}

A cross-sectional study was conducted in selected areas in Kattankulathur Block, Chennai. The Kattankulathur block is a revenue block in the Kanchipuram district of Tamil Nadu, India. It has a total of 39 panchayat villages with a population of 197,596 population. Five villages were selected for the study. After the initial screening, simple random sampling technique was adopted to select the study participants.

The sample size was calculated based on the pilot study results and also computed through power analysis. The sample size was estimated by power analysis before the commencement of the study. The estimated sample size was 111 , considering the attrition rate of $10 \%$, the sample size was rounded to 130 . The total sample for the study comprised 130 postmenopausal women. The inclusion criteria for sample selection include (a) women who attained permanent cessation of menstruation, (b) women with the age group of 45-55 years, and (c) women who are presenting with physical and psychological symptoms such as hot flushes, sweating, insomnia, anxiety, and depression. The exclusion criteria include (a) women with gynecological problems such as fibroid uterus, dysfunctional uterine bleeding, and prolapsed uterus, (b) women who are on hormone replacement therapy, and (c) who are on medical treatment for relieving symptoms of menopause.

\section{ETHICAL CONSIDERATION}

Formal approval was obtained from the Institutional review board and Institutional Ethical Committee. Both written and verbal information about the study were given in local language to women, who participated in this study. Women were requested to participate voluntarily in the study. The objectives, practices, goodness, problems, and time period involved in practice were explained in the consent form. They were informed that they have a right to withdraw at any time during the course of the study.

\section{INSTRUMENTS}

The questionnaire for the present research study comprises three sections. Section I pertained information regarding demographic data such as age, religion, marital status, type of family, availability of support system, age of menarche, parity, and duration of attainment of menopause.

Section II assessed the level of stress of postmenopausal women by Sheldon Cohen's Perceived Stress Scale (PSS) [11]. PSS is the most widely used psychological instrument for measuring the perception of stress. The scale consists of 10 items pertaining to stress of postmenopausal women with a severity ranging from 0 to 4 (0 - Never, 1 - Almost never, 2 - Sometimes, 3 - Fairly often, 4 - Very often). The participants were asked to indicate the level of severity of stress in the scale provided. The reliability of the tool was obtained by test-retest method and a reliability coefficient of 0.80 was found to be statistically significant.

Section III was related to assessment of QOL of postmenopausal women. Standardized the WHO QOL - BREF questionnaire [12] in Tamil version was used for the study without any modifications. The formal permission was obtained from the WHO for using the scale for this study. The scale contains 26 items under 4 domains such as physical domain, psychological domain, social domain, and environment domain. Out of 26 items, 23 items were positively scored and 3 items (item number 3,4 , and 26 ) were negatively scored in the scale. The first two items that were examined separately: Item 1 asked about an individual's overall perception of QOL and item 2 asked about an individual's overall perception of menopausal women's health. Other 24 items were included in the domains. Domain scores are scaled in a positive direction (higher scores denote higher QOL). The mean score of items within each domain is used to calculate the domain score. Mean scores are then multiplied by 4 to make domain scores and subsequently transformed to a 0-100 scale using the formula. Domain wise interpretation of data was done by using various statistical methods.

\section{Statistical package}

Statistical Package for the social sciences (SPSS) version 16, IBM, Chicago, USA, and Instat were used for data analysis. The results are presented as percentages, mean, and standard deviation. Pearson correlation coefficient was used for assessing the relationship between stress and QOL. $\mathrm{p}<0.05$ was considered as statistically significant.

\section{RESULTS}

Out of 130 participants, two of them withdrew from the study due to change in residency and illness. Data analysis was performed for the remaining 128 participants.

The mean age of women was $49.42 \pm 2.71$. Most of them $87(68 \%)$ belonged to Hindu religion, $71.1 \%$ of them were married, 80 (62.5\%) belonged to nuclear family, and relatives were the major support system for most of them (43\%). The mean age of menarche was $13.19 \pm 1.95$, majority $62(48.4 \%)$ were multiparous women, and most of them $63(49.2 \%)$ attained menopause within 1-2 years of duration.

Table 1 showed that the majority of postmenopausal women 90 (70.4\%) had very high level of stress and 38 (29.6\%) of them had a high level of stress.

It is inferred from Table 2 that maximum of postmenopausal women $56(44 \%)$ had very poor QOL, $39(30 \%)$ of them had neither poor nor good QOL, 28 (22\%) experienced poor QOL, and only 5 (4\%) of them had good QOL (item number 1). Regarding the satisfaction and the health status, maximum of postmenopausal women 59 (46\%) were very dissatisfied about their health, 33 (26\%) were dissatisfied, $30(23 \%)$ were neither satisfied nor dissatisfied, and only $6(5 \%)$ of them were satisfied about their health (item number 2).

Table 3 depicted the domain-wise QOL of postmenopausal women. The results revealed that the lower mean scores were found in physical domain $(40.84 \pm 7.71)$, psychological domain $(39.00 \pm 14.52)$, social domain (39.04 \pm 18.26$)$, and environment domain (35.87 \pm 17.89$)$ among postmenopausal women. The overall scores were $38.69 \pm 14.60$. 
Table 4 showed that there was moderate negative correlation found between stress and QOL in postmenopausal women.

\section{DISCUSSION}

The menopause is an opportunity for the fullest blossoming of a woman's power, wisdom, and creativity. It is a bridge to a new phase of life when many women report feeling more confident, empowered, and energized. The onset of menopause heralds a time of diminished estrogen exposure, which may have both acute and chronic effect on health and QOL. The majority of women reports hot flushes developing with increasing severity in the menopausal transition and becoming incessant in the years following last menstrual period. Observational studies suggest that as many as $75 \%$ of women will experience hot flashes after menopause. Left untreated, the most women will have spontaneous cessation of hot flashes within 5 years, although some

Table 1: Frequency and percentage distribution of level of stress of postmenopausal women $n=128$

\begin{tabular}{ll}
\hline Level of stress & n (\%) \\
\hline Very low stress & - \\
Low stress & - \\
Average stress & - \\
High stress & $38(29.6)$ \\
Very high stress & $90(70.4)$ \\
\hline
\end{tabular}

Table 2: Distribution of quality of life and satisfaction regarding health status of postmenopausal women (QOL, item no.: 1 and 2) $n=128$

\begin{tabular}{ll}
\hline QOL of postmenopausal women & n (\%) \\
\hline QOL (Item no.: 1) & $56(44)$ \\
Very poor & $28(22)$ \\
Poor & $39(30)$ \\
Neither poor nor good & $5(4)$ \\
Good & - \\
Very good & $59(46)$ \\
Satisfaction regarding health status (Item no.: 2) & $33(26)$ \\
Very dissatisfied & $30(23)$ \\
Dissatisfied & $6(5)$ \\
Neither satisfied nor dissatisfied & - \\
Satisfied & \\
Very satisfied & \\
\hline QOL: Quality of life &
\end{tabular}

Table 3: Domain wise QOL of postmenopausal women $n=128$

\begin{tabular}{lll}
\hline Domains of quality of life & Mean & SD \\
\hline Physical domain & 40.84 & 7.71 \\
Psychological domain & 39.00 & 14.52 \\
Social domain & 39.04 & 18.26 \\
Environment domain & 35.87 & 17.89 \\
Overall & 38.69 & 14.60 \\
\hline
\end{tabular}

SD: Standard deviation, QOL: Quality of life

Table 4: Correlation between level of stress and QOL in postmenopausal women $n=128$

\begin{tabular}{llll}
\hline Variables & $\begin{array}{l}\text { Correlation } \\
\text { coefficient }\end{array}$ & p value & Interpretation \\
\hline QOL versus stress & -0.599 & $0.000^{* *}$ & $\begin{array}{l}\text { Moderate negative } \\
\text { correlation between } \\
\text { QOL and stress }\end{array}$ \\
\hline *Significant at $\mathrm{p} \leq 0.05,{ }^{* *}$ High significance at $\mathrm{p} \leq 0.01$. Q0 L: Quality of life
\end{tabular}

women continue to experience distressing symptoms for 30 years or more $[13,14]$.

The current study showed that the majority of postmenopausal women $90(70.4 \%)$ had very high level of stress. Maximum of postmenopausal women $56(44 \%)$ had very poor QOL and 59 (46\%) were very dissatisfied about their health status. The lower mean scores were found in physical, psychological, social, and environment domain among postmenopausal women. There was moderate negative correlation found between stress and QOL among postmenopausal women. It shows that, when the stress was increased, poor QOL was experienced by postmenopausal women.

The study findings were consistent with the study conducted by Chen, et al. conducted a study to assess the impact of menopause, age, and other factors on QOL in China. In general, healthy women aged 35-64 years were recruited. An instrument including the Chinese version of the menopause-specific QOL questionnaire was used to obtain data A gradual decline of QOL was seen from pre- to peri- and post-menopausal women in the same age group. Statistically impaired QOL was associated with the peri- and post-menopausal women in vasomotor and physical domains but only with the postmenopausal women in psychosocial and sexual domains. The early postmenopausal women presented the worse QOL in vasomotor, psychosocial, and physical domains. The gradually declining sexual QOL was related to the advance of menopause [15].

\section{CONCLUSION}

This study results showed that the majority of postmenopausal women $90(70.4 \%)$ had very high level of stress. The lower mean scores were found in physical, psychological, social, and environment domain among postmenopausal women. The stress during menopause negatively affected the QOL of postmenopausal women.

\section{REFERENCES}

1. Available from: https://www.my.clevelandclinic.org/health/hic-whatis-perimenopause-menopause-postmenopause.

2. Available from: https://www.en.wikipedia.org/wiki/Menopause.

3. Available from: https://www.menopause.org/women/ menopauseflashes/stress-getting-serious-about-solutions.

4. Francina S. Yoga and the wisdom of menopause. A Guide to Physical, Emotional and Spiritual Health at Midlife and Beyond. Florida: Health communications, Inc.; 2003.

5. Rogers CD. Breathing exercises for anxiety in menopause, 2011. Available from: https://www.Livestrong.com.

6. WHOQOL-BREF Introduction, Administration, Scoring world Health Organization, December, 1996. Available from: https://www.who.int/ mental health/media/en/76.pdf

7. Abedzāeh Kalarhoudi M, Taebi M, Sadat Z, Saberi F. Assessment of quality of life in menopausal periods: A population study in kashan, iran. Iran Red Crescent Med J 2011;13(11):811-7.

8. Conde DM, Pinto-Neto AM, Santos-Sá D, Costa-Paiva L, Martinez EZ. Factors associated with quality of life in a cohort of postmenopausal women. Gynecol Endocrinol 2006;22(8):441-6.

9. Yoga for menopause - cope with menopause through yoga. Available from: https://www.abc-of-yoga.com

10. Beck M. Dc Stress, Menopause symptoms and your Adrenal glands menopause. Available from: https://www.about.com/od/ managingmenopausal stress.

11. Cohen S, Kamarck T, Mermelstien R. A global measure of perceived stress. J Health Soc Behav 1993;24:386-96.

12. WHOQOL-BREF- Introduction, Administration, Scoring and Generic Version of the Assessment. Available from: http://www.who.int/ mental health/media/en/76.pdf.

13. Robert LR. Menopause. Clinical Gynecology. Philadelphia: Elsevier, Churchill Livingstone; 2006.

14. Sengupta BS, Chattopadhyay SK, Varma TR. Menopause. Gynaecology for Post Graduates \& Practitioners. $2^{\text {nd }}$ ed. New Delhi: Elsevier; 2007. p. 292-300.

15. Chen $\mathrm{Y}$, Lin SQ, Wei Y, Gao HL, Wang SH, Wu ZL. Impact of menopause on quality of life in community-based women in China. Menopause 2008;15(1):144-9. 